\title{
Hydrological Hazards in a Changing Environment: Early Warning, Forecasting, and Impact Assessment
}

\author{
Slavisa Trajkovic, ${ }^{1}$ Ozgur Kisi, ${ }^{2}$ Momcilo Markus, ${ }^{3}$ Hossein Tabari, ${ }^{4}$ \\ Milan Gocic, ${ }^{1}$ and Shahaboddin Shamshirband ${ }^{5}$ \\ ${ }^{1}$ Faculty of Civil Engineering and Architecture, University of Niš, Aleksandra Medvedeva 14, 18000 Niš, Serbia \\ ${ }^{2}$ Faculty of Architecture and Engineering, Canik Başarı University, Gürgenyatak Köyü, Canik, 55080 Samsun, Turkey \\ ${ }^{3}$ University of Illinois at Urbana-Champaign, 2204 Griffith Drive, Champaign, IL 61820, USA \\ ${ }^{4}$ Department of Civil Engineering, University of Leuven, Kasteelpark Arenberg 40, P.O. Box 2448, 3001 Leuven, Belgium \\ ${ }^{5}$ Faculty of Computer Science and Information Technology, University of Malaya, 50603 Kuala Lumpur, Malaysia
}

Correspondence should be addressed to Slavisa Trajkovic; slavisa@gaf.ni.ac.rs

Received 12 June 2016; Accepted 13 June 2016

Copyright (C) 2016 Slavisa Trajkovic et al. This is an open access article distributed under the Creative Commons Attribution License, which permits unrestricted use, distribution, and reproduction in any medium, provided the original work is properly cited.

Hydrological hazards of various types present a myriad of technical and public policy issues worldwide. Defined as extreme events associated with water occurrence, movement, and distribution, hydrological hazards include droughts and flooding and related events (e.g., landslides and river scour and deposition). Hydrological hazards and their impacts are associated with climate variability, demographic trends, land-cover change, and other causative factors and could be exasperated by global climate change. The increase in greenhouse gases in the atmosphere will continue leading to global warming and an intensification of the hydrological cycle, making hydrological extreme studies more complex and challenging.

Because of the immense impacts of hydrological hazards on society and its economies, it is important to consider novel approaches, techniques, or methods for the prediction, prevention, and mitigation of hydrological extremes. Given the complexity of the nonstationary hydrometeorological and hydroclimatological processes, it is critical to utilize recent technological developments and scientific knowledge to improve our understanding of hydrological hazards and our ability to cope with droughts and floods.

In this special issue, ten papers are collected that cover the hydrological hazards in a changing environment. This collection includes the following topics: regional flood/drought analysis, methodologies for the prediction and prevention of hydrological extremes, early warning and forecasting systems for hydrological extremes, case studies in different parts of the world, emerging technologies in data analysis, hydroinformatics, and climate informatics and effects of climate change and land-use/land-cover changes.

Flood hazard mapping of the Mert River Basin, Samsun, Turkey, was investigated using GIS and HEC-RAS in the paper by V. Demir and O. Kisi (2016). 3D hazard maps were obtained for the Q10, Q25, Q50, and Q100 floods. The flood maps demonstrated that some areas are highly affected by flooding resulting from a low return period (Q10) event.

B. S. Kim et al. (2016) identified drought characteristics by applying the threshold level method and projecting the drought risk of each administrative division in South Korea in the 21st century.

W. Yu et al. (2016) investigated the uncertainty propagation of a rainfall forecast into hydrological response with catchment scale through distributed rainfall-runoff modeling based on the forecasted ensemble rainfall of a numerical weather prediction (NWP) model. This study is carried out and verified using the largest flood event by typhoon "Talas" of 2011, Shingu River Basin, Japan.

N. Diodato et al. (2016) established thresholds in the power of rainstorms to discern the spatial patterns of a rainfall erosivity hazard in the Rhone region (eastern France). Climate fluctuations of rainfall erosivity revealed possible 
signals of increased storminess hazards across the region in recent times.

L. Tadić et al. (2016) analysed the small catchment area in the Croatian lowland with its hydrological characteristics in the period between 1981 and 2014 to define the significance of change in hydrological and meteorological parameters and water balance components.

H. Jia and D. Pan (2016) used the wavelet transform technique to analyse precipitation data for nearly 60 years (19542012) in the Yunnan Province of China. According to the main cycle of summer and the annual rainfall, precipitation of Yunnan is in the decreased oscillation period; local drought may also occur in the future.

N. Ožanić et al. (2016) investigated the possibility of implementing the early warning system (EWS) in a smallscale catchment in Croatia and developed the methodology for a hydrological prediction model based on an artificial neural network (ANN).

F. Vemado and A. J. P. Filho (2016) analysed the Metropolitan Area of São Paulo (MASP) heat island (HI) effect and its interaction with the local sea breeze (SB) inflow in rainfall amounts and deep convection.

M. Gocic et al. (2016) presented a spatial pattern of the precipitation concentration index (PCI) in Serbia. For the purpose of PCI prediction, three Support Vector Machine (SVM) models were developed and used.

S. Kolaković et al. (2016) analysed the exploitation of documented historical floods for achieving better flood defense at the catchment of the Tisza River (Hungary and Serbia).

\section{Acknowledgments}

As guest editors of this special issue, we would like to thank all the authors for their contributions to this volume. Special mention of thanks and appreciation is due to the international panel of reviewers for making their expertise available for evaluation of the manuscripts.

Slavisa Trajkovic Ozgur Kisi

Momcilo Markus

Hossein Tabari

Milan Gocic

Shahaboddin Shamshirband 

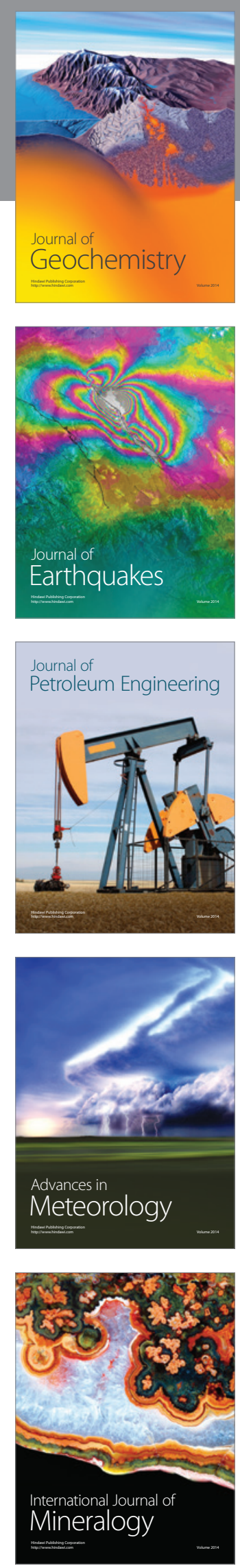
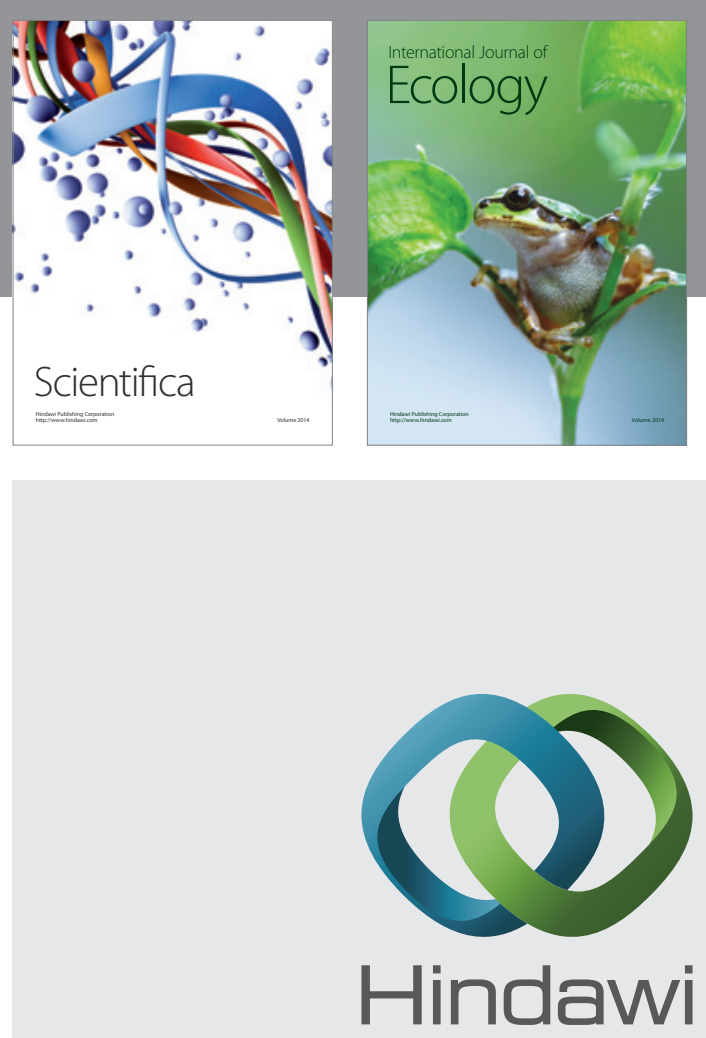

Submit your manuscripts at

http://www.hindawi.com
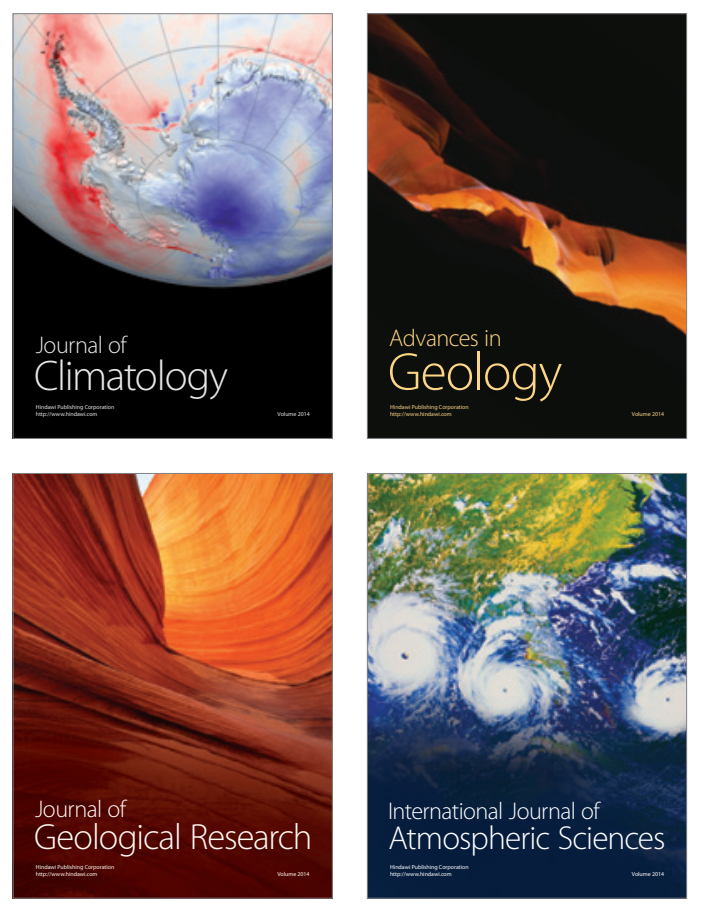

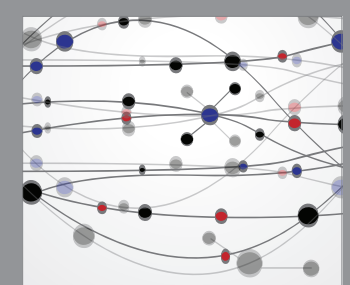

The Scientific

\section{World Journal}
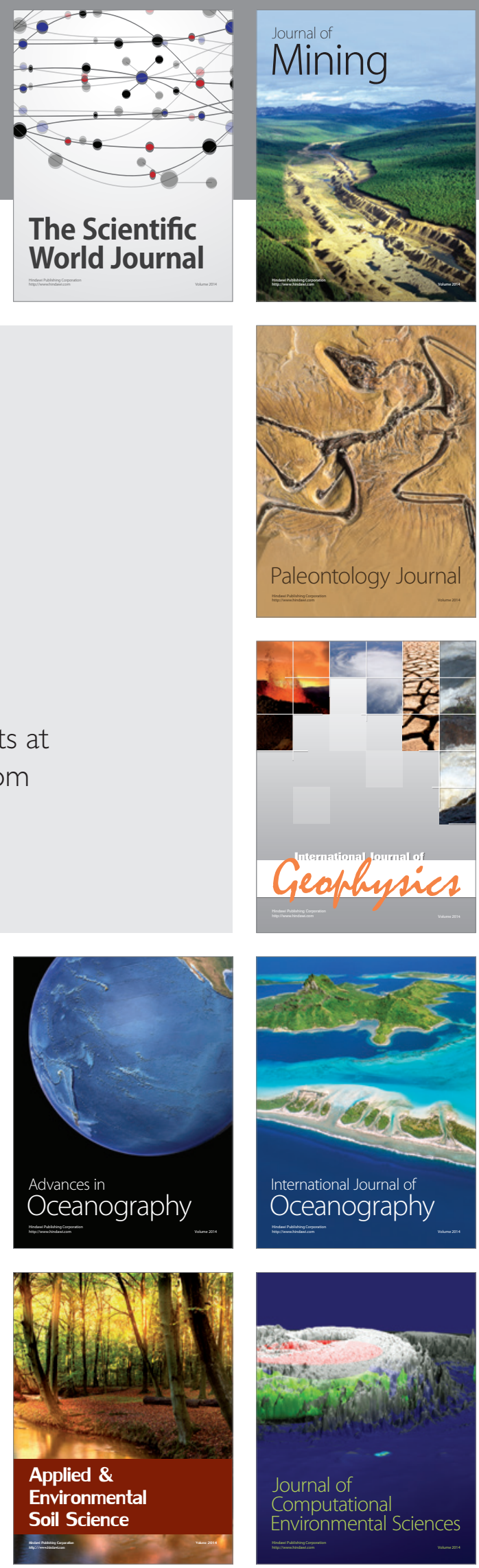